\title{
Defining the Landscape of Translation ${ }^{1}$
}

Alan Melby (LTAC)

Paul Fields (LinguaTech)

Daryl Hague (BYU)

Geoffrey S. Koby (KSU)

Arle Lommel (independent scholar)
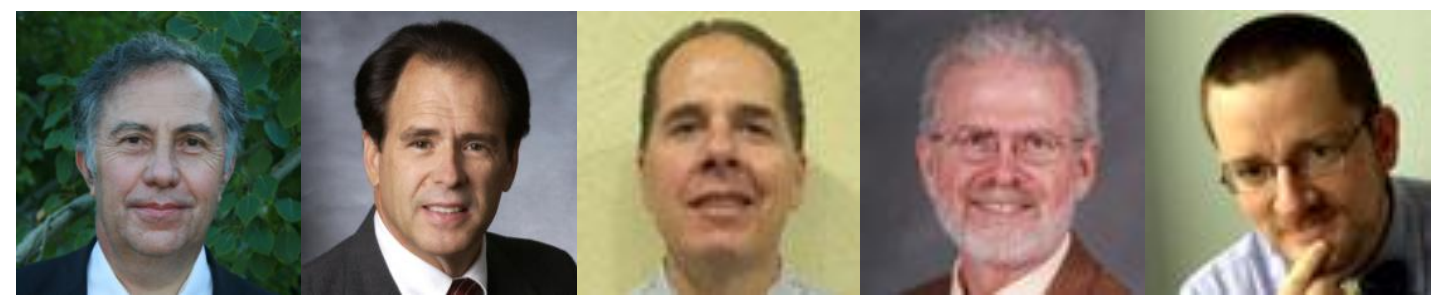

\section{ABSTRACT}

This article is the first in a three-part series on translation quality. The articles build on one another by addressing definitions of translation, quality, and finally translation quality. Concerning the meaning of translation, many definitions have been proposed in the translation-studies literature. This article, however, is not a literature review. Instead, it makes a contribution by describing a "landscape" within which various definitions of translation can be "planted." This landscape is delimited by two axes-namely, scope and specifications-and provides a framework for discussing such questions as (a) the relationship between translation and localization and (b) the role of translation specifications. Within that landscape, this article presents two opposing views about the definition of translation. The authors disagree about which of these views is more useful, but they agree that stakeholders must clearly define translation before they can meaningfully address translation quality.

Keywords: Translation, Localization, Definition, Multimodal Translation, Translation-Plus, Adaptation, Transcreation, Narrow, Broad

\section{RESUM (Tot definint el paisatge de la traducció)}

Aquest article és el primer d'una sèrie de tres articles sobre qualitat en traducció. Els articles se succeeixen entre si i tracten la definició de traducció, qualitat i finalment qualitat en traducció. En relació amb el significat de traducció, en la literatura dels estudis de traducció s'han proposat moltes definicions. No obstant això, aquest article no és una revisió de la bibliografia. Per contra, suposa una contribució que consisteix a descriure un "paisatge" en què diverses definicions de traducció es poden "sembrar". Aquest paisatge està delimitat per dos eixos, que són l'abast i les especificacions, i proporciona un marc per discutir qüestions com a) la relació entre traducció i localització i b) el paper de les especificacions en traducció. Dins d'aquest paisatge, aquest article presenta dues postures oposada sobre la definició de traducció. Els autors no arriben a un acord sobre quina d'aquestes postures és més útil, però coincideixen que les parts interessades han de definir amb claredat el concepte de traducció abans de poder tractar la noció de qualitat en traducció de forma significativa.

Paraules clau: traducció, localització, definició, traducció multimodal, plus en traducció, adaptació, transcreació, narrow, broad.

\footnotetext{
${ }^{1}$ This article is the first of trilogy of papers published in this issue: Melby et al., Fields et al., and Koby et al.
} 


\section{RESUMEN (La definición del paisaje de la traducción)}

Este artículo es el primero de una serie de tres artículos sobre calidad en traducción. Los artículos se suceden entre sí y tratan la definición de traducción, calidad y finalmente calidad en traducción. En relación con el significado de traducción, en la literatura de los estudios de traducción se han propuesto muchas definiciones. No obstante, este artículo no es una revisión de la bibliografía. Por el contrario, supone una contribución que consiste en describir un "paisaje" en el que varias definiciones de traducción se pueden "sembrar". Este paisaje está delimitado por dos ejes, que son alcance y especificaciones, y proporciona un marco para discutir cuestiones como a) la relación entre traducción y localización y b) el papel de las especificaciones en traducción. Dentro de este paisaje, este artículo presenta dos posturas opuesta sobre la definición de traducción. Los autores no llegan a un acuerdo sobre cuál de estas posturas es más útil, pero coinciden en que las partes interesadas deben definir con claridad el concepto de traducción antes de poder tratar la noción de calidad en traducción de forma significativa.

Palabras clave: traducción, localización, definición, traducción multimodal, plus en traducción, adaptación, transcreación, narrow, broad.

\section{Introduction}

During a session on translation quality at the 2014 World Congress of the International Federation of Translators, a member of the audience stated that the localization industry has nothing to do with the translation industry. This statement probably reflected the speaker's belief that translation is a text-centric activity. That belief enjoys support within the language industry, but such support is not universal. This lack of agreement has important implications for measuring translation quality. Specifically, language service providers need to measure translation quality, yet they must first define translation before they can determine its quality.

The present article and its two companions reflect a lively three-month debate among the authors about defining translation and translation quality and about the relevance of quality management to the translation industry. Given the authors' backgrounds in practical research and development in translator productivity tools, professional translation, academic translation studies, quality management, and business analytics, the debate reflects our experience in all these areas. We failed to reach consensus on definitions but agreed that reporting about the debate was important. Concerning that debate, the present article presents two opposing views about how the term translation should be defined. The follow-up articles discuss the discipline of quality management and how translation quality should be defined. We have attempted to make these articles accessible to people in both translation studies and the translation industry, and we hope that this series will spark further discussion regarding how to define translation and translation quality.

Defining translation might seem to be a simple task at first blush, but as in many fields, the definition involves a fundamental question of boundaries. For centuries, people have frequently viewed translation as applying only (or at least primarily) to written texts. Many theories of translation have come and gone, but most have emphasized the notion of "carrying meaning across." This notion reflects the etymological sense of translate from the combination of Latin trans ('over') plus the verbal root lat, the past participle of ferō ('bear'). This etymological meaning commonly influences many languages' terms for translation. In other words, the notion has been that there is a meaning encoded or present in the source text that has to be conveyed in the target text. More recent theories of translation have moved away from the notion of meaning being encoded in the text. Nevertheless, these theories have focused on transferring intended or understood meaning associated with a text by a reader or writer. This meaning-transfer approach to defining translation inevitably leads to discussions about the nature of meaning. 
In this article, we will neither pursue a discussion of meaning nor review the long list of attempts at defining translation that have appeared in the translation studies literature over the past several decades. Space limitations simply do not allow us to do so. Instead, we will report our debate within a framework that represents a novel contribution to translation studies. That framework posits that various definitions of translation can be conceptually placed in a landscape defined by two axes: scope (narrow-to-broad) and specifications (absolute-torelative).

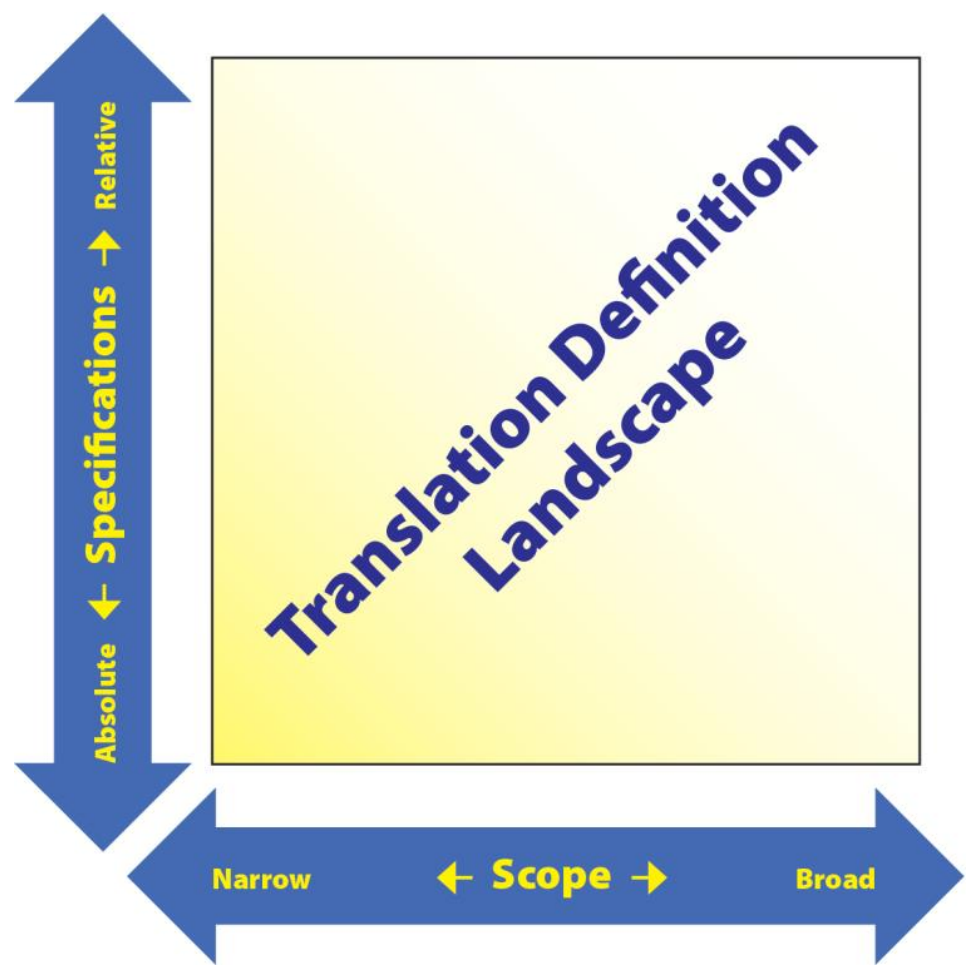

Figure 1. The landscape of definitions of translation

Axis 1: Scope (Narrow-to-Broad)

The traditional understanding of translation as a text-centric activity is common today. Indeed, Anthony Pym notes that many people in the localization industry promote the traditional idea that translation is simply "converting text from one language into another" (51) or replacing "natural-language strings" (52). Since the 1980s, however, additional activities associated with text translation have complicated the traditional understanding. These additional activities include the process of adapting software for a locale - a variation of a language combined with cultural conventions found in a particular region. This adaptation process is generally known as localization. With respect to software, language service providers frequently combine text with other culture- or region-specific content, such as graphics, music, currencies, or functional elements (e.g., forms for entering addresses and telephone numbers). These content items-meaning the combination of text and optional non-textual items-must be altered for software to work effectively in various locales.

The issue of software localization's relationship to the boundaries of translation does not concern text itself. After all, embedded texts clearly need to be translated, no matter how one defines translation. Instead, software localization's relationship to translation concerns nontextual items. For example, consider a computer sports game featuring a scene in which the 
winner is serenaded with the "Star Spangled Banner" (the U.S. national anthem). That scene would need to be changed for players in other countries, who would find the U.S. anthem inappropriate for their own countries. Similarly, different cultures associate different meaning with various colors, bodily gestures, animals, etc. All of these elements potentially need to be adjusted for different locale-specific audiences.

But do the adjustments required for localization qualify as "translation" or something else? The process of adjusting non-textual items undoubtedly has some similarities to classic textual translation. For example, as in textual translation, localization requires bicultural knowledge and an understanding of the semantics of the items being adjusted. Nevertheless, such adjustment goes beyond plain text. For that reason, language-industry professionals have differing views about localization's relationship to translation.

Using social media, we recently conducted an informal survey of some professionals involved with localization. In that survey, we asked respondents to describe localization's relationship to translation. Respondents answered in one of three ways, all of which received significant support: (1) localization is superordinate to translation (i.e., translation is part of localization); (2) localization is separate from-but partially overlaps with-translation; (3) translation includes localization.

One way to evaluate the foregoing views is to locate them on a continuum between strictly textual translation and tasks such as localization that involve adapting non-textual content. One pole of the continuum would be translating plain-text files, while the other would be something like adapting a rich multimedia presentation. Most items would exist somewhere between these poles. Once parties agree to these poles, they can debate the question of how much and what kinds of non-textual adaptation fall under the purview of "translation."

Adding to the complexity of this adaptation question is the related issue of how much one can adapt a text beyond a straightforward transfer of perceived meaning. That is, how much can one adapt and still claim to be engaged in translation? Consider, for example, that an advertising campaign designed for Spain may be substantially re-conceptualized to create a functionally equivalent campaign for the U.S. Such a re-conceptualization may completely change many aspects of the Spanish campaign, although some text may be simply translated. This process of re-conceptualization is often known as "transcreation" and, in its most extreme forms, may result in something that is only loosely tied to the original in its details.

Both localization and transcreation are related to translation, but are they part of a broader and more inclusive definition of translation? Conversely, are localization and transcreation special skills separate from the core activity of translation, but still included in the larger language industry? Different parties will have different answers to these questions. As a result, the place of processes like transcreation is likely to remain controversial. For that reason, theorists and practitioners addressing translation should be clear about their definition of "translation." In particular, they should indicate whether they are using a narrow notion of purely textual translation or using a broader notion of "multimodal translation" (O'Sullivan 7), which includes elements beyond text, such as images.

\section{A Broad Definition of Translation}

A broad definition of translation would be as follows (see section on second axis for a discussion of specifications):

Translation is the creation of target content that corresponds to source content according to agreed-upon specifications.

Under this broad definition, all of the following processes and products would qualify as "translation":

- professional human translation

- raw machine translation 
- post-edited machine translation, including fully and lightly post-edited machine translation

- localization

- full translation (where the target text generally includes a sentence for each source-text sentence)

- summary translation (as done extensively in the U.S. government)

- gisting (a "quick and dirty" translation by a human or a machine, often used to decide whether to request a professional, publication-ready translation)

- scientific/technical translation

- legal translation

- literary translation

- transcreation (as in advertising)

- overt translation (House 1997); foreignized (Venuti 1995); exoticized (Nord 2001)

- covert translation (House 1997); domesticated (Venuti 1995)

This broad definition of translation allows for both textual translation and non-textual adaptation, so long as the content to be translated includes some text. It is based on Functionalism (Nord 1997). Translation viewed broadly can be called multimodal translation to distinguish it from traditional text-only translation.

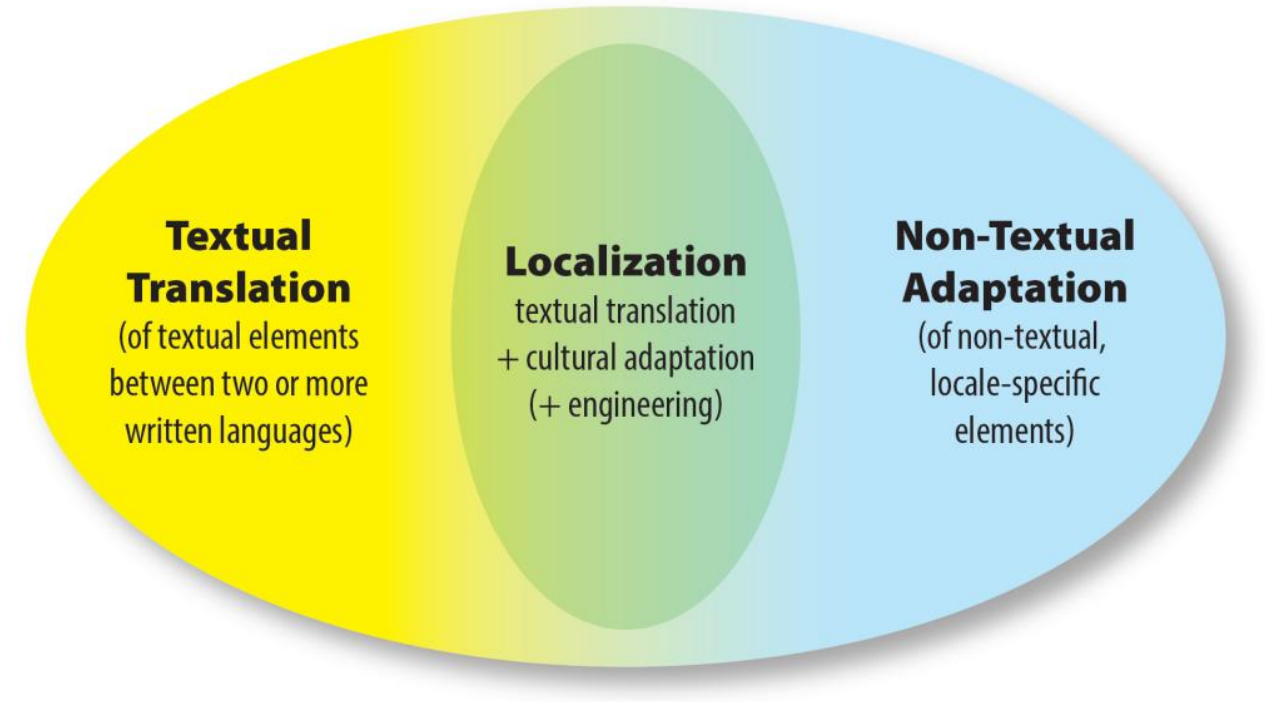

Figure 2. A broad view of translation-based on the broad definition-that includes localization.

Given the many processes and products that qualify as translation under this broad view, the term "source text" is not sufficient to describe a translation's antecedent. Instead, the terms "source content" and "target content" are much more apt. Indeed, the language industry uses these terms with increasing frequency. This usage makes sense, as the language industry employs the terms translation and localization regardless of how they are defined.

With respect to this broad view, some may note that it shares some commonality with Gideon Toury's description of "assumed translations" (27). According to Toury, such translations include "all utterances in a [target] culture which are presented or regarded as translations, on any grounds whatsoever, as well as all phenomena within them and the processes that gave rise to them" (27). Toury's view is admittedly broad. Furthermore, it is helpful for the 
corpora studies for which it was intended. However, Toury's view does not provide a framework for contrasting more specific definitions. In addition, it cannot provide a foundation for measuring translation quality objectively and reliably across graders. For these reasons, it is not very suitable either for the translation industry or for translator education.

\section{A Narrow Definition of Translation}

In contrast to the broad view described above, narrow views of translation distinguish between translation per se and other activities. These views are also based on Functionalism, but interpret the scope of translation differently. One such narrow view labels these other activities as "translation-plus." In this translation-plus view, translation per se can be defined as follows:

Translation transfers a written source text into a written target text of roughly equivalent length. Such a translation conveys all the source text's meaning, making only those adjustments necessary for cultural appropriateness without adding, omitting, condensing, or adapting anything else.

In contrast to translation per se, "translation-plus" activities generally do not convey all of a source text's meaning. These "translation-plus" activities include summarization (viewed as condensing material after translation) and transcreation (thought of as modifying the original message in creative ways after translation).

To understand how translation-plus works, consider the case of a translation produced for an audience and purpose different from its source text. Translation-plus posits that such a translation requires two separate operations: (1) translation per se, which is an actual transfer of meaning - translation unit by translation unit-from source text to translated text; and (2) a separate adaptation process, which may involve a change in audience (e.g., children vs. adults), purpose (e.g., intelligence gathering vs. exhortation), or form (e.g., full text vs. summarization or gisting). This view may seem to suggest that a complete target text is always physically produced, but such is not the case. Translation-plus simply affirms that the translation process and the adaptation process are different. For example, summarization may occur in the source language before a translated text is written. In such a case, a summarized (mental) source text is translated into the target language.

\section{A “Translation-Plus" Approach Based on a Narrow Definition of Translation}

Making a claim as to where translation should be located along the scope (narrow-tobroad) axis is important to professional translators, translation studies, and the translation industry. After all, the scope of translation could very well affect how clients perceive what professional translators do. The authors supporting a broad view argue that the narrow view is dangerous because it could marginalize the profession. For example, customers seeking localization services could bypass professional translators skilled in localization and instead look for "localizers." Those supporting a narrow view counter that a broad view is problematic for translation studies and for the translation industry. They note, for example, that translators typically specialize. Legal translators, for example, do not localize or transcreate, nor do they need to do so. Under this narrow view, textual translation is the core activity of professional translators, while activities such as summarization, localization, transcreation, and postediting machine translation are supplementary skills that only some translators require. Furthermore, products like raw machine translation, which would qualify as translation under a broad view, would not be considered translation under a narrow view. 


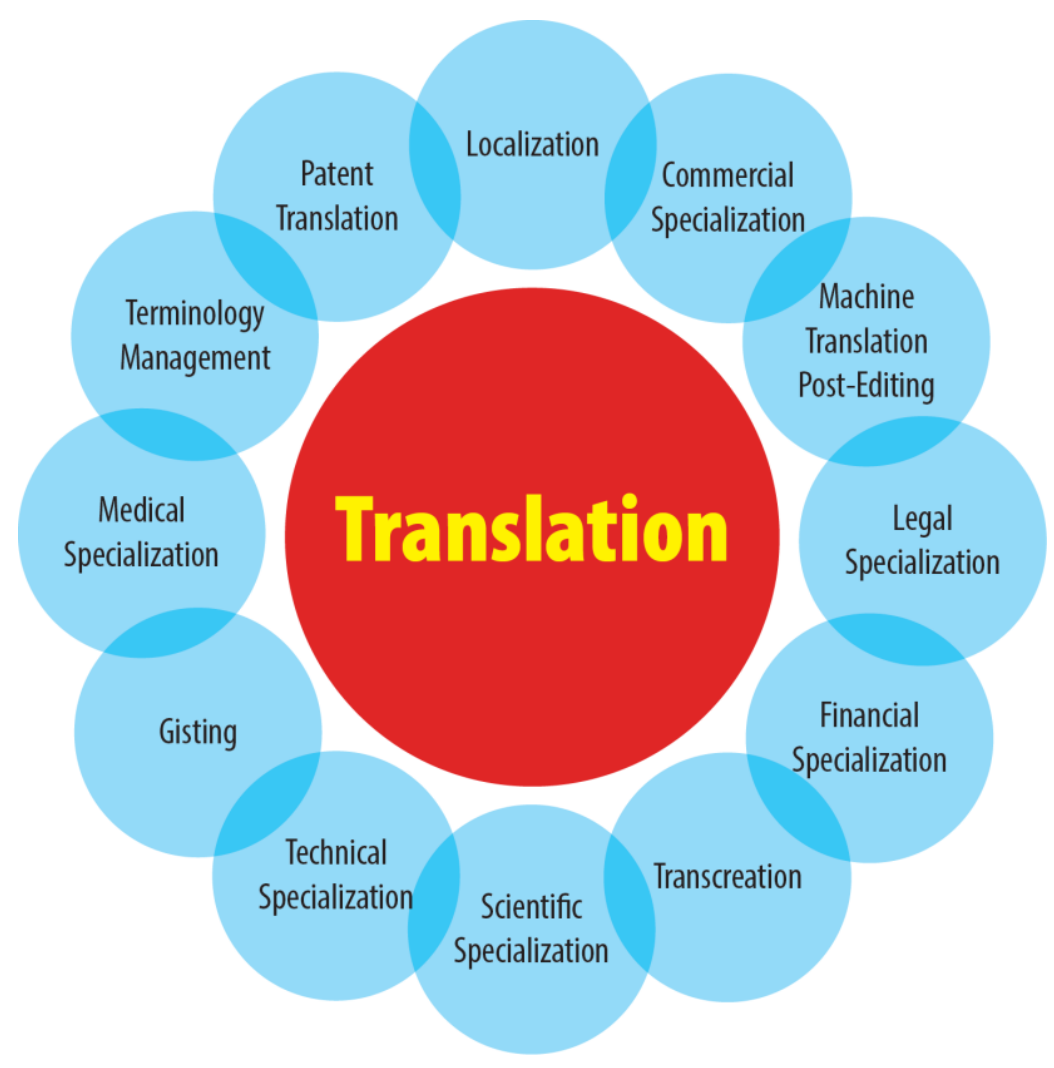

Figure 3. The translation industry with translation at its core (based on a narrow definition of translation)

Axis 2: Specifications (Absolute-to-Relative)

The second axis to consider with respect to defining translation is the extent to which translation must consider specifications. Specifications define what is expected in a translation. Without specifications, details of the translation may be undefined and lead to confusion. Stakeholders employ specifications to shape the contours of a particular translation. The principal issue here is whether absolute specifications exist for all translations or whether specifications should vary relative to particular tasks.

Closely tied to the broad definition of translation given above is the notion of structured translation specifications. This article's appendix lists 21 translation parameters that appear in several standards. According to the broad view of translation described above, each of these parameters can vary independently. In particular, the following eight parameters for target content can take on a variety of values, depending on the project:

- Target language (parameter 6)

- Audience (parameter 7)

- Purpose (parameter 8)

- Register (parameter 10)

- Format, including file format and modality (parameter 11)

- Layout (parameter 13)

- Style (parameter 12)

- Content correspondence (parameter 9) 
The specifications associated with the last two parameters listed-style and content correspondence-can vary considerably from project to project. However, attention to accuracy and fluency applies to both of these parameters. With respect to style, specifications assume that the target content's textual aspect exhibits a minimal level of fluency (readability and correctness of the target text as a stand-alone document) determined by the audience and purpose. With respect to content correspondence, specifications assume that the target content's textual aspect exhibits a minimal level of accuracy (correspondence between the source text and the target text), also determined by the audience and purpose.

A simple example illustrates how the minimal baselines delimit the boundaries of translation. Imagine that after commissioning a literary translation to promote understanding of Don Quixote, a customer receives a treatise on Babylonian cosmogony (the origin of the universe). Not even the broad definition described above would accept that treatise as a translation. In contrast, Toury's view might label this cosmogony as a translation in the sense of a creative interpretation of Cervantes' underlying message.

While even our broad view would reject the Babylonian cosmogony as a translation, the broad definition of translation in this article would nevertheless allow considerable variation in content correspondence for other types of activities, such as movie subtitling. In English-toGerman subtitling, standards require that content be shortened by approximately $30 \%$ so that subtitles remain short enough to be read at a comfortable rate. For that reason, subtitling specifications instruct translators to prioritize content and seek compact solutions. As a result, subtitle translators may omit information they consider of lesser importance even though such deliberate omissions would be considered a mistake in most other cases.

Narrow and broad views of translation characterize the subtitle translator's task quite differently. A narrow view considers it an example of "translation-plus": translation plus condensation. A broad view, on the other hand, simply sees the subtitling task as a type of translation without regard to whether one or two steps are involved. This difference between narrow and broad becomes pronounced as one considers other examples of specifications.

One such example is translation of time-critical intelligence information for government or business requesters. In such cases, specifications may prioritize the timely delivery of accurate translations, even if that priority leaves the translations "unpolished" or somewhat lacking in fluency. A narrow view of translation might characterize this task as "translation-minus," although a translator would require great skill to produce such a translation and to know what source-text aspects to emphasize. In contrast, a broad view would simply see summarization and gisting as examples of translation with very different specifications. This view does not equate summarization and gisting. Rather, the broad view grants the label "translation" to activities having different priorities with respect to accurate meaning, just as the U.S. government recognizes in its own summarization rules (see http://www.casl.umd.edu/stet).

Other cases may likewise adjust the priority of accurate meaning. For example, the specifications for translating a popular song's lyrics would likely prioritize meter, rhyme, and emotional content over precise accuracy. Nevertheless, if the purpose of translating a song is to analyze how the lyrics discuss some topic, the specifications would likely emphasize accurate meaning rather than fluency or artistry.

In all of the foregoing cases, successful translation requires knowledge of specifications. That is, translators cannot provide the best translation for the job without knowing what is expected. Recognizing this situation, researchers and language professionals generally agree that in many cases, sensitivity to a given set of specifications is essential to discussing and defining translation with respect to a task. However, the authors of this article disagree with each other on whether there are any specifications that are absolute in that they are constant, need not be stated, and do not depend on either the audience or purpose of the translation.

Thus, the principal issue regarding the specifications axis is whether there are any absolutes in specifications. In other words, what requirements, if any, apply to all translation- 
related activities? The only generally agreed-upon requirements are fluency and accuracy. Accuracy is tied to the scope (narrow-to-broad) axis. Specifically, a narrow view of translation undoubtedly allows for the possibility of an absolute accuracy requirement. For some types of content correspondence, however, such as summarization and transcreation, a broad view does not allow for a single standard of accuracy.

Like accuracy, the requirement of fluency is tied to the scope axis. A narrow view of translation permits an absolute requirement of maximal fluency for the target text. Proposed translations that do not meet this absolute requirement would be considered unacceptable. In contrast, a broad view of translation accepts the barely readable content of raw machine translation so long as that content meets users' purposes. One such purpose, gisting using raw machine translation, would be helping users on a limited budget choose which documents in a collection they would like to have translated by a professional translator.

The foregoing discussion of accuracy and fluency harks back to the primary issue concerning the specifications axis: are there any requirements that can be established in advance as requirements for all translations, regardless of whether one takes a broad or narrow position on the scope axis? According to both views, the answer is yes. The difference is that with the narrow view, a minimum threshold of accuracy and fluency is established to which all translations must aspire, regardless of audience and purpose. If a text fails to meet this threshold, the text is not merely a bad translation; rather, it does not qualify as a translation at all. With the broad view, the thresholds vary according to purpose.

Machine translation provides an interesting case for the view that a universal threshold exists. Raw machine translation often does not transfer meaning accurately. By way of illustration, Google Translate rendered the previous (italicized) sentence into German in a way that mostly obscured the meaning after the verb: "Rohe maschinelle Übersetzung oft nicht übertragen bedeutet genau." In English, the German rendering could read as follows: "[Such translation] often not transfer what exactly means." Can this text be called a "translation" if the reader knows that the topic is MT but has no idea what is said about it? If some requirements are non-negotiable and this MT text fails to meet those requirements, that text cannot be called a translation. However, no consensus has been reached among the authors with respect to absolute requirements for accuracy and fluency that do not depend on audience and purpose.

Yet another issue regarding specifications concerns whether they need to be explicit. If a translator can reliably infer some specifications, then do they need to be stated explicitly? One answer is that only specifications that cannot be inferred should be stated explicitly. A contrasting view is that because many stakeholders are involved in a translation project, chances are high that different people may infer different specifications; as a result, specifications should always be explicit.

\section{Conclusion}

Two axes, scope (narrow-to-broad) and specifications (absolute-to-relative), define a "landscape" for describing various definitions of translation. We have described two positions in this landscape: (1) a definition with broad scope allowing for specifications to vary widely relative to audience and purpose; and (2) a definition with a narrow scope based on a core set of absolute specifications. These two definitions are not equivalent to each other. In particular, according to the narrow definition, neither summary translation nor raw and lightly post-edited machine translation are translations at all. They are instead part of "peritranslation." Also, the narrow definition excludes localization from translation while the broad definition includes it. The co-authors are divided on which definition is preferable. Other definitions are conceivable based on other points in the landscape delimiting translation and should be described in follow-up discussions to this article. 
The co-authors do agree on the following: even if two parties cannot agree on how to define translation, they should indicate where their respective definitions are "planted" in this landscape. Furthermore, the parties should carefully define translation (and what they mean by "quality" in general) before attempting to define translation quality. If people do not take these steps, they will likely speak past each other, wasting time and energy on needless disagreements. For example, a discussion of translation quality restricted to the work of professional human translators, excluding raw or lightly posted machine translation, localization, and summarization, is a very different discussion than one that includes all of these elements.

\section{References}

O'Sullivan, Carol. 2013. "Introduction: Multimodality as Challenge and Resource for Translation." Jostrans: The Journal of Specialized Translation 20:2-14.

House, Juliane. 1997. Translation Quality Assessment: A Model Revisited. Tübingen: Gunter Narr.

Nord, Christiane. 1997. Translating as a Purposeful Activity: Functionalist Approaches Explained. Manchester: Jerome Publishing.

Nord, Christiane. 2001. "Dealing with Purposes in Intercultural Communication: Some Methodological Considerations." Revista Alicantina de Estudios Ingleses 14:151-66.

Pym, Anthony. 2004. The Moving Text. Amsterdam: John Benjamins.

Toury, Gideon. 2012. Descriptive Translation Studies-and beyond. Rev. ed. Amsterdam: John Benjamins.

Venuti, Lawrence. 1995. The Translator's Invisibility: A History of Translation. London: Routledge. 


\section{Appendix: Translation Parameters Associated with a Broad Definition of Translation}

(For more information about these translation parameters and how they relate to specifications for translation projects, see www.ttt.org/specs or ASTM F2575 [www.astm.org technical committee F43] or ISO/TS 11669 [www.iso.org technical committee 37)] or Annex B of the forthcoming ISO 17100)

\section{A. Linguistic product parameters [1-13]}

Source-content information [1-5] (much of this can be inferred by examining the source content)

1. textual characteristics

(a) source language (including locale information, such as UK vs. American English)

(b) text type (class to which a text is assigned based on its function, format, or the specific intention of the author with respect to the target audience, e.g. annual report)

(c) audience

(d) purpose (Skopos)

2. specialized language

(e) subject field

(f) terminology (terms marked in the source text, without target-language equivalents)

3. volume (i.e. size or length in words, characters, or some other unit)

4. complexity (e.g. written by a non-native of the source language? Text embedded in graphics?)

5. origin (e.g. the source text is itself a translation)

\section{Target content requirements [6-13]}

6. target language requirements

(g) target language (including locale, e.g. Canadian French)

(h) target terminology (project-specific bilingual terminology)

7. audience (especially as it differs from intended audience of the source content)

8. purpose (especially when it differs from the purpose of the source content)

9. content correspondence (assumes a degree of accuracy appropriate to type: full segment-by-segment translation, summary, overt, covert, raw machine translation, etc.)

10. register (from formal to familiar; tone used in addressing audience)

11. format (file and modality (file format: Word, InDesign, etc.; modality: document, subtitles, etc.)

12. style (within the baseline of a level of fluency appropriate to audience and purpose)

(i) style guide (e.g. Chicago Manual of Style or a company guide)

(j) style relevance (is a high degree of readability important in this case?)

13. layout (margins, headings, etc.)

\section{B. Process tasks [14-15]}

14. typical tasks (note: if post-editing is involved, it falls in 14b, not 14c)

(k) preparation

(l) initial translation (MAHT using tools, HAMT post-editing, or raw machine translation)

(m) in-process quality assurance (revision [bilingual], review [monolingual], proofreading)

15. additional tasks (e.g. third party review, terminology check, software testing, or back translation)

\section{Project Environment [16-18]}


16. technology (is any particular technology to be used in the project?)

17. reference materials (translation memories, termbases to supplement that in $6 \mathrm{~b}$, etc.)

18. workplace requirements (e.g. security measures, safety concerns)

\section{Project Stakeholder Relationships [19-21]}

19. permissions

(n) copyright (who holds copyright for target text, translation memory, etc.?)

(o) recognition (does the translator's name appear in the published translation?)

(p) restrictions (on the use of materials, such as translation memory, after the project, etc.)

20. submissions

(q) qualifications (expected or required qualifications of provider)

(r) deliverables (the target content in the specified format, updated termbase, etc.)

(s) delivery method (email, sFTP, etc.)

(t) delivery deadline(s)

21. expectations

(u) compensation (typically, cost)

(v) communication (channels and mode among stakeholders) 